\title{
The application of generic process models in Business Process Re-engineering
}

\author{
$S J$ Childe, A M Weaver, $R$ S Maull, P A Smart, J Bennett \\ University of Plymouth \\ Drake Circus, Plymouth, PLA 8AA, United Kingdom \\ Tel +44 1752232618 e-mail stevec@soc.plym.ac.uk
}

\begin{abstract}
Research work is proceeding on the development of a framework that will help manufacturing businesses identify business processes, process components and links between the processes to form a company-wide view. This paper describes the supporting theory of systems and the structure, development and validation of a model of standard business processes.
\end{abstract}

\section{Keywords}

Business Process Re-engineering; process model; manufacturing; SME; IDEF $_{0}$

\section{INTRODUCTION}

The objective of this paper is to describe the development of generic process models for Business Process Re-engineering (BPR) that will encourage companies and participants carrying out BPR projects to take a business process perspective. It will address specifically the application of BPR within Small and Medium Sized Enterprises.

The authors believe that the issue of how to encourage individuals at all levels within a company to think in terms of business processes is critical to the success of a BPR project. This is pointed out by Rummler and Brache (1990) who have found that;

"When we ask a manager to draw a picture of his or her business (be it an entire company, a business unit or department), we typically get something that looks like the traditional organisation chart."

A number of multi-national companies have successfully used generic process models to intervene and change processes within business units, for example Xerox and Shell. The purpose of these generic process models is to encourage individuals within the business units to think in terms of business processes and to provide a starting point for process redesign. The business process view gives the individuals a holistic view of the activities that are carried out within the business units. The authors believe that the use of generic process models could be applied just as successfully by Small and Medium Sized Manufacturing Enterprises (SMEs) to provide a process framework and intervention tool for BPR projects. 
The initial problem is to identify which SMEs may benefit from undertaking a BPR project. SMEs have very different characteristics compared to large organisations especially in the area of innovation (Lefebvre et al 1990, Meredith 1987).

Mount et al (1993) provide a framework to deal with this issue which consists of five typical phases of small business development.

1 Owner Operated The owner manages the business and also performs many of the day-today productive activities with a small workforce.

2 Transition to owner-managed The owner's role is changing to a state in which the owner is engaged in managing the business full-time, yet the business is small enough not to require a middle level of management.

3 Owner-managed The owner is engaged full-time in the management activities within the business. Supervisory roles may exist but there are no formal functional boundaries.

4 Transition to emergent functional The company is becoming too big to be managed by the owner. Functional boundaries become defined and hence a middle layer of management is required. The addition of specialist middle managers demands substantially more delegation of decision making. In this case the owner is often obliged to screen the viewpoints of senior functional managers and to arbitrate some consensus on a final course of action.

5 Emergent functional organisation A company in which defined functions and managers and a clear organisation structure exists. Middle management is established and functions have frequently established their own objectives, mission statements etc. There may be a conflict of interest between functions, and political manoeuvring may be widespread.

We believe that companies where such conflicts and complexity are emerging are those who may benefit from BPR programmes. The generic models have therefore been developed with emergent functional organisations in mind.

\section{GENERIC PROCESSES}

In the majority of documented BPR methodologies, including those developed by Coopers \& Lybrand, IBM, British Telecom, Xerox and Lucas, one of the initial activities is to identify the core business processes. In identifying the core processes the participants in the BPR project are defining boundaries within their organisation using a process perspective.

By comparing the sets of core processes produced by companies that have undertaken BPR projects, a hierarchy of common processes that are generic across the companies becomes evident. This suggests that a set of standard processes may evolve in process oriented organisations, in the same way that a roughly standardised set of functional divisions (manufacturing, design, sales and marketing, finance, personnel, etc.) developed.

\section{AN ARCHITECTURE OF BUSINESS PROCESSES}

A manufacturing company can be represented at the most abstract level as a process which transforms inputs into outputs to satisfy the objectives of the various organisational stakeholders. The organisation can be sub-divided into a number of sub-processes that 
interact to meet these overall objectives. An overall structure or architecture allows each process to be considered without losing the context of its purpose within the whole organisation. The process view of an organisation ensures a strong emphasis on how work gets done and is a "revolutionary change of perspective" from the traditional functional based view of an organisation (Davenport 1993).

There are many examples of organisations identifying a hierarchy of business processes. It is one of the initial activities in the majority of documented BPR including those developed by Coopers \& Lybrand (Johansson et al 1993), IBM (Kane 1986), British Telecom (Harvey 1994), Xerox and Lucas (Parnaby 1993). The number of business processes identified at the various levels within the hierarchy varies considerably from organisation to organisation. Davenport (1993) gives a number of reasons for this variation:

- Processes within organisations are almost infinitely divisible.

- The identification of processes can be exploratory and iterative.

- An organisation seeking to carry out incremental changes is likely to focus on improvements in sub-divisions of processes whereas for radical changes an organisation should attempt to define processes as broadly as possible.

Examples of process identification by organisations can be found in Davenport (1993) and the Business Intelligence report on BPR (Harvey 1994) and many case studies in journal articles, for example Shapiro et al (1992), Davenport and Short (1990).

Two activity types "primary" and "support" activities are identified by Porter in his "value chain" concept (1985). The "primary activities" are those activities that interface with the external customer and add value to a product either by designing, manufacturing or by selling the product. The "support activities" are those activities that enable the primary activities to function.

"Management" activities represent a third type of process, including activities which do not directly add value to the customer, the direction setting, enabling change or managing performance activities. For example Veasey (1994) refers to "Management, Support and Value Adding" processes; Royal Mail have "External Customer, Support and Management" processes; Lucas have "Development, Delivery Operations and Support" processes; Pagoda (1993) have "Manage, Operate and Support" processes. The CIM-OSA standard (AMICE ESPRIT 1989) also groups processes into "Manage, Operate and Support".

The grouping of the processes under "Manage, Operate and Support" emphasises some of the general characteristics of the processes and the approaches to redesigning the different types of processes may be different. For example, the concept of value-added must be applied differently in the Operate and Manage areas. Paradoxically, the grouping of processes is a functionally based analysis rather than a process analysis and must be seen as less important than the analysis of the processes themselves.

\subsection{The "Operate" processes}

The "Operate" processes are those processes which directly produce value for customers. Value is added if activities lead directly to the fulfilment of a customers requirements. The core operational processes identified by Champy (1995) and Meyer (1993) for a business are "customer service", "product development", and "order fulfilment". The "customer service" process transforms knowledge of customer requirements and the market into customer orders. The "product development" process transforms the actual or perceived requirements of a 
customer into a design that can be manufactured. The "order fulfilment" process takes the order, manufactures and delivers the product to the customer.

The focus of the work in developing a set of generic processes has been on the "Operate" processes because these are the processes where greatest gains in competitive advantage can be made (Hammer and Champy 1993, Meyer 1993, Johannson et al 1993). Analysis of these processes will also

illuminate the most important support process impediments and do so within the

context of meeting customer needs (Meyer 1993)

A recent survey (Harvey 1994) also showed that the most commonly cited processes that organisations were targeting for re-engineering included customer service, logistics and new product development.

From our discussions with companies and our comparison of the lists of core processes developed by a number of organisations including Xerox, IBM and Rover, many companies further divide the "customer service" process into two parts. The two parts are the process of getting an order from a customer and the process of providing support to the customer after the order has been fulfilled. We have called these processes the "Get Order" process and the "Support Product" process.

We have thus identified a set of four "Operate" processes within a manufacturing company. We have named each one with an imperative verb so that the process names are consistent with the $\mathrm{IDEF}_{0}$ models. The four "Operate" processes are

- Get Order

- Develop Product

- Fulfil Order

- Support Product

\subsection{Process definition}

There are many different views of what should be included or excluded within the boundaries of each process. Each organisation is likely to have a different view. To describe a consensus view of the "Operate" processes we are developing a precise description using a root definition and an $\mathrm{IDEF}_{0}$ model of each of the processes showing activities and flows in each process and between the four processes. These are intended to provide what Wilson (1984) terms a "Consensus Primary Task Model".

To develop a rigorous definition of each process, a "root definition" of the process was defined. The concept of a "root definition" is part of the Soft Systems Methodology (SSM) described by Checkland (1981). A root definition should be a "concise description of a human activity system which captures a particular view of it" (Checkland 1981). Checkland also developed a mnemonic CATWOE by which the six elements that should be covered in a root definition can be remembered. The six elements paraphrased from Checkland are;

- Customers of the process, beneficiaries or victims affected by the processes activities.

- Actors or agents who carry out or cause to be carried out the main activities of the process.

- Transformation, the means by which defined inputs are transformed into defined outputs.

- Weltanschauung, the outlook or framework that makes the root definition meaningful.

- Ownership, the agency having a prime concern for the system and the ultimate power to cause the system to cease to exist.

- Environment, features of the environment of the process that must be taken as given. 
Since the generic process models stem form the same work, the Actors, Weltanschauung and Ownership for each are the same. The Actors in each process are the people and machines within the manufacturing company under consideration. These cannot be defined more precisely, as the model has to preserve its generic nature. The Weltanschauung for each model is the same, that is to say they are all intended to be more helpful than a neutral model which would be acceptable to all manufacturing companies, but which in its theoretically wide application would lose all meaning. Rather it is intended to produce a consensus model which will accommodate the Weltanschauung of the majority of manufacturing companies. Ownership can only be expressed as the owner of the manufacturing company. In some specific cases, process owners may be created which provide the owner role for a particular process, but this can not be seen as a general concept until the process architecture is generally accepted, thus, it can not be part of it.

The root definitions that capture the view of the authors with respect to the "Operate" processes of any manufacturing company is as follows;

The "get order" process contains activities performed by humans and machines. Its principal transformations are to transform a product or concept of a product into a customer order, to translate customer requirements into a form meaningful to the other processes and to use market data to identify potential requirements for new products. It includes the flow of information that is required to satisfy a customer by providing information to the customer and to the other "Operate" processes. The process constantly seeks to ensure that customers' requirements are met and that there are sufficient orders to meet the stakeholder requirements.

The "develop product" process contains activities performed by humans and machines. Its principal transformation is from knowledge into the specification of a product that can be produced to meet customer requirements. It includes the flow of information to enable development of the specification of a product that can be manufactured and the development of product concepts that may fulfil future customer requirements. The process constantly seeks to provide specifications for products that will meet the requirements of customers whilst balancing stakeholder requirements.

The "fulfil order" process contains activities performed by humans and machines. Its principal transformations are product orders into products and enquiries into specifications. It includes the flow of both the material and the information that result in the fulfilment of the external customer order or enquiry. The process constantly seeks to fulfil customer requirements whilst balancing stakeholder requirements.

The "support product" process contains activities performed by humans and machines. Its principal transformation is a need for support into a product that continues to meet the requirements of a customer. It includes the flow of the resources and information that are required to meet the customer's support requirements. The process constantly seeks to fulfil the customer's support requirements whilst balancing stakeholder requirements.

In the tradition of Checkland's Soft Systems Methodology, the root definitions are being revised as more knowledge about the processes is gained. 


\section{DEVELOPMENT AND VALIDATION OF THE PROCESS MODELS}

\subsection{Modelling technique}

The model of the "Operate" processes has been developed using IDEF $_{0}$ (CAM-I 1980). $\mathrm{IDEF}_{0}$ is widely used in the manufacturing sector for modelling processes. $\mathrm{IDEF}_{0}$ comprises:

- A set of methods that assist in understanding a complex subject;

- A graphical language for communicating that understanding;

- A set of management and human-factor considerations for guiding and controlling the use of the technique.

$\mathrm{IDEF}_{0}$ uses top-down decomposition to break-up complex topics into small pieces which can be more readily understood and which are set in their proper context with respect to other system elements. An $\mathrm{IDEF}_{0}$ model is an ordered collection of diagrams, related in a precise manner to form a coherent model of the subject. The number of diagrams in a model is determined by the breadth and depth of analysis required for the purpose of that particular model. At all times the relationship of any part to the rest of the whole remains visible.

In summary $\mathrm{IDEF}_{0}$ provides the ability to show what is being done within a process, what connects the activities and what constrains activities. It uses a structured set of guidelines based around hierarchical decomposition, with excellent guidance on abstraction at higher levels. If used well this ensures good communication and a systemic perspective.

\subsection{Level of analysis}

The level of analysis is critical when developing a generic model. For the generic model to be of any use it must contain elements which are at a level of detail that allows meaningful discussion within a particular company. Conversely, too much detail would restrict its application. A very detailed model would become specific to a particular company. Thus an attempt is being made to judge the appropriate level of detail.

Using $\mathrm{IDEF}_{0}$ as a modelling technique ensures that the context for any part of a process model under analysis in relation to the whole of the process model is always known. Therefore a company can focus on the part of a process model it is particularly interested in and develop a further levels of detail without losing its context within the whole process.

\subsection{Information sources}

The models have been developed with the involvement of a number of manufacturing companies varying in size from Times 1000 companies to Small and Medium Manufacturing Enterprises (SMEs) with under 500 employees.

The information used to develop the process models has been extracted and assimilated from a number of sources including literature (especially Harrington 1984, CAM-I 1984, Porter 1985), previous work (Childe 1991), generic models described in other modelling methods and individual models of company processes.

The IDEF $_{0}$ models of the "Operate" processes will cover all four types of manufacturing companies defined by Wortmann (1990); Make-to-stock, Assemble-to-order, Make-to-order and Engineer-to-order.

\subsection{IDEF $_{0}$ standard process models}

The "Operate" processes are represented in a single $\mathrm{IDEF}_{0}$ model that shows the interactions between each of the processes and external customers, suppliers and other parts of the 
organisation that are outside the boundaries of the model. $\mathrm{IDEF}_{0}$ has allowed us to develop a model of each process separately and then combine the $\mathrm{IDEF}_{0}$ models into an integrated model of the "Operate" processes. The complete model includes a set of $\mathrm{IDEF}_{0}$ diagrams and a glossary of terms.

\section{$5.5 \quad$ Validation}

The validation of the process models is currently being carried out. Validation methods include criticism and comment by academic colleagues and industrial practitioners experienced in BPR and manufacturing management and a comparison by third parties to their own process models.

\section{APPLICATION}

In the introduction the critical issue of getting employees to think in terms of business processes was identified. The generic process models are intended to be used as an intervention tool to encourage the participants of a BPR project within a manufacturing company to take a business process perspective. The participants in a BPR project would generally be individuals from the functions who currently perform activities within the process, guided by objectives set by senior management.

In the initial stages of the BPR project, following the identification of a core process to be redesigned, the participants would be presented with the generic process model and glossary of terms and asked to compare the generic process model against the activities within the company. These activities would be carried out under the guidance of an internal or external facilitator.

In carrying out a comparison the model encourages the participants to;

- Take a business process perspective as the generic model provides an existing process framework.

- Develop a consensus view of their own company's process by debating the differences between the generic model and each participants perceived view of the company's process.

- Identify and change the generic model to represent their company's process.

- Identify immediate changes that could be made to the company's process as differences between the model and reality are found.

- Consider the systemic relationship of all parts of the process as model provides a structured medium where inconsistencies in the changed model can be identified easily. In comparison with current BPR approaches where the participants are encouraged to develop a process model of the existing business process, the use of generic models reduce the danger of participants reverting to tradition functional thinking by providing a process focused framework. It also provides greater momentum to the project than a "blank sheet of paper" and the generic process model is non-political having being produced externally. The non-political nature of the generic process model should enable participants to more freely criticise the model and in doing so generate debate and understanding amongst the group. 


\section{CONCLUSION}

This paper has described the development of a set of generic process models for business process re-engineering in small and medium sized manufacturing companies. Initial validation of the models has supported the view that generic models would be useful in the re-engineering of SME's and the models have raised considerable interest. Further development and validation of the models is proceeding.

\section{Acknowledgements}

The research work described in this paper has been jointly funded by the Engineering and Physical Science Research Council under a grant (GR/J/95010) entitled "Specification of a Business Process Re-engineering methodology for Small and Medium Sized Manufacturing Enterprises" and British Aerospace (Systems and Engineering) Ltd.

\section{REFERENCES}

AMICE ESPRIT (1989) : CIM-OSA Reference Architecture

CAM-I (1980), Architect's Manual ICAM Definition Method "IDEF-0", Arlington, Texas

CAM-I (1984), A study program for defining a computer integrated manufacturing (CIM) generic concept for electronic products, Arlington, Texas

Champy J (1995), Re-engineering Management, HarperBusiness, NY

Checkland P (1981), Systems Thinking, Systems Practice, J Wiley \& Sons

Childe S J (1991), The design and implementation of manufacturing infrastructures, $\mathrm{PhD}$ Thesis, Polytechnic South West, UK

Culverhouse P F, 1993, Four design routes in electronics engineering product development, Journal of Design and Manufacturing, Vol 3

Davenport T H and Short J E (1990), The new industrial engineering: information technology and Business Process Redesign, Sloan Management Review, Summer

Davenport T H (1993), Process Innovation, Harvard Business School Press

Hammer M, Champy J (1993), Re-engineering the corporation, HarperCollins, NY

Harrington J (1984), Understanding the manufacturing process, Marcel Dekker Inc.

Harvey D (1994), Re-engineering: The Critical Success Factors, Business Intelligence

Johansson H J, McHugh P, Pendlebury A J, Wheeler W A (1993), Business Process Reengineering-BreakPoint Strategies for market dominance, J Wiley \& Sons

Kane E J (1986), IBM's Quality Focus on the Business Process, Quality Progress, April

Lefebvre L A, Lefebvre E, Poupart R (1990), The shape of the new winner: Innovativeness and strategic edge in small firms, National Productivity Review, Vol 9 No 3

Meredith J (1987), The strategic advantages of new manufacturing technologies for small firms, Strategic Management Journal, Vol 8, pp249-258

Meyer C (1993), Fast Cycle Time, The Free Press, NY

Mount J, Zinger J T, Forsyth G R (1993), Organising for development in the small business, Long Range Planning, Vol 26 No 5, pp 111-120

Pagoda Associates Ltd (1993), Pagoda Process Management Report, London

Parnaby J (1993), Business Process Systems Engineering, Lucas Industries plc, November Porter M E (1985), Competitive Advantage: Creating and Sustaining Superior Performance, 
The Free Press, NY

Rummler G A \& Brache A P (1990), Improving Performance, Jossey-Bass

Shapiro B P, Rangan V K, Sviokla J J (1992), Staple yourself to an order, Harvard Business Review, July-August

Veasey P W (1994) Managing a programme of business re-engineering projects in a diversified business, Long Range Planning, Vol 27 No5

Wilson B (1984), Systems: Concepts, Methodologies and Applications, J Wiley

Wortmann J C (1990), Towards One-of-A-Kind Production: The Future of European Industry, Advances in Production Management Systems, Elsevier Science Publishers, Holland 


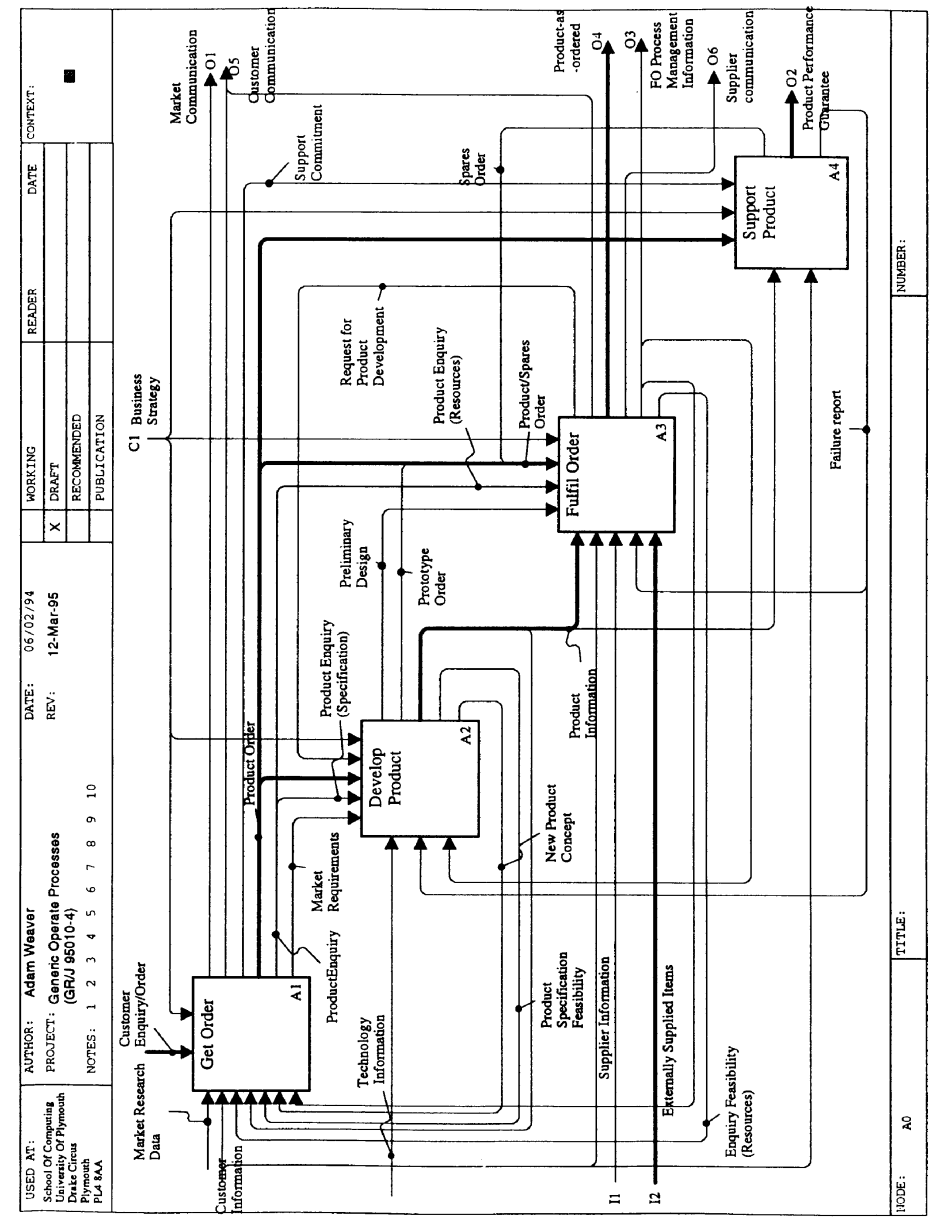


The authors are members of a research team at the University of Plymouth engaged upon various research projects in the field of systems modelling and design in manufacturing and service industries. Current projects are in the areas of business process re-engineering in SME's, production management, concurrent engineering and manufacturing strategy. Current collaborators include manufacturing companies, software companies, financial institutions and hospitals.

Dr Steve Childe is a Postdoctoral Research Fellow in the School of Computing, University of Plymouth. His research interests lie in the area of manufacturing and business systems, including Business Process Re-engineering and Computer Aided Production Management. Dr Childe is a grant holder on EPSRC Grant GR/J95010 "Specification of a BPR Methodology for SMEs". He is a founder member of the European Operations Management Association and a member of IFIP's Working Group 5.7 (Computer Aided Production Management). 